\title{
Comparison of Quantitative Changes after passing the Laser Beam through Polymeric Material
}

\author{
Libuše Sýkorová ${ }^{1}$, Jana Knedlová $^{1, *}$, Dagmar Měřínská ${ }^{1}$, and Vladimír Pata ${ }^{1}$ \\ ${ }^{1}$ Tomas Bata University in Zlín, Faculty of Technology, Vavrečkova 275, 76001 Zlín, Czechia
}

\begin{abstract}
The article focuses on laser machining of various polymeric materials. Specifically, it examines the possibility of undesirable changes in these materials as, due to the concentrated energy of the laser beam, the heat of the material is also transferred to the material near the cutting point and hence to the heat of the cut. Although the polymeric materials do not have a high thermal conductivity, it can be expected that due to the elevated temperature, different structural or chemical changes may occur near the cutting edge. Some high-molecular substances begin to split into low-molecular-weight products, and depolymerisation or degradation of the may occur. All these changes may have a negative impact on the product performance. The "Infrared Vibrational Spectroscopy" and X-ray Diffraction Analysis" were selected for experimental machining and subsequent assessment of possible change in selected polymer materials.
\end{abstract}

\section{Introduction}

When removing the material the form of energy used is based on the naked eye invisible particles. No direct contact between the tool and the workpiece is used to form the surface of the material. The principle of the material removal is the effect of the high energy beam on the surface. [1]

When machining materials, thee laser is used as a carrier of intense electromagnetic radiation, which is directed to a particular object. The effect of the laser depends on the nature of the workpiece material (its physical properties, structure, etc.), the parameters of the laser itself, and is machining, surface quality assessment and possible change in the vicinity of the cut; the part of the laser beam that is absorbed by the material is a key aspect with respect to the material. [1] Certain types of polymeric materials are brittle at normal temperatures, with more burdens and strains. With increasing temperature, these polymers become more ductile, more elastic. The properties of these materials are therefore temperature-dependent. In some temperature areas, changes occur faster or they may be going step-by-step.

Because of the increasing temperature, the polymers begin to soften, and may in some cases increase the kinetic energy of the macromolecular chain until it overcomes the intermolecular forces and the polymer obtains properties and behavior that are very close to

* Corresponding author: knedlova@utb.cz 
the properties and behavior of the liquid. There may also occur a change in the structure of the polymers by starting some high-molecular substances to break down into lowmolecular-weight products. Sometimes, monomer cleavage can occur. However, this may exist without changing the chemical composition of a particular polymer. The tendency to depolymerize up to the monomer, without changing the chemical composition, also has a PP. The depolymerization takes place by a chain reaction in which the monomer is released from the ends of the macromolecular chains. [2]

For experimental machining, PP material was chosen as a representative of semicrystalline polymers. For the subsequent assessment of possible structural changes in the material after laser beam irradiation, the FTIR (Fourier Transform Infra-Red) FTIR spectroscopy method was selected. The Nicolet Avatar 320 FT-IR was used investigate surface using the FTIR vibration method. The influence of the laser beam structure in the terms of examining the crystal structure change was assessed using the PANalytical $\mathrm{X}^{`}$ Pert PRO diffractometer.

\section{Material Polypropylene}

The radical or cationic polymerization of propylene yields products consisting of branched, atactic molecules. Ziegler-type catalysts are capable of polymerizing propylene to highmolecular polymers with a regular structure, high melting point and good mechanical properties. Differences in properties of different propylene are given by the spatial arrangement of substituents. Isotactic PP has all the methyl groups on the same side in the plane bounded by the backbone. Polypropylene is a crystalline polymer with a degree of crystallinity of 60 to $70 \%$, which causes opacity of this material. Its chemical composition is evident from Fig. 1. [3]

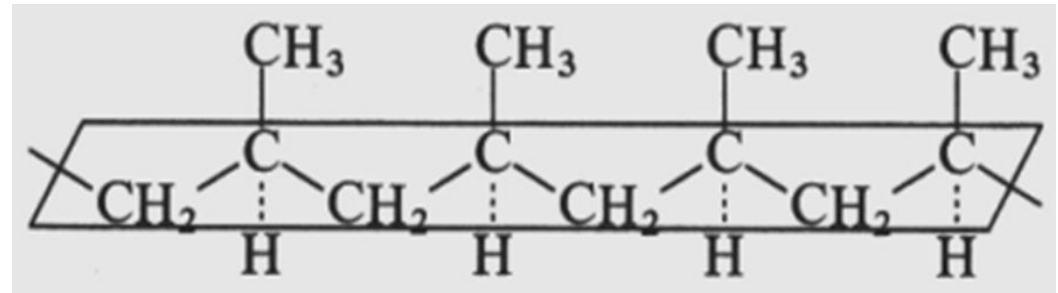

Fig. 1. Formula PP [3]

The non-polar structure of this material exhibits excellent electro-insulating properties over a wide range of frequencies. It also has a good resistance to boiling water and sterilization with water vapor. Its thermal applicability is in short use to $135^{\circ} \mathrm{C}$, in longterm $100{ }^{\circ} \mathrm{C}$. PP has a much lower tendency to corrode under tension than other polyolefins, has a higher hardness and bending strength, but a lower impact toughness.

PP can be used for various products that require stiffness, mechanical strength and good electrical insulation properties. Applied in automotive (instrument panels, fans), consumer industries (parts of vacuum cleaners, hair dryers, mixers, toys). Thanks to resistance to sterilization temperatures, PP can be used to make syringes. [3]

\section{Sample preparations}

Samples were made using device ILS 3NM, having a wavelength $\lambda=10.6 \mu \mathrm{m}$ and with a maximum power $P=100 \mathrm{~W}$, maximum cutting speed $f=1524 \mathrm{~mm}$. $\mathrm{s}^{-1}$. Three grooves, 
marked with numerals 1 through 3, were created with laser machine the ILS 3NM at different cutting speeds $f$ and the same power $P$ (refer to: Table1, Fig.2). These grooves were then cut by a band saw to allow access to the cutting site. FTIR measurements were performed in grooves 1 and 3. For comparison of FTIR and RTG results a basic material uninfluenced by the laser was selected.

Table 1. Technological parameters

\begin{tabular}{|l|c|c|c|}
\hline \multirow{3}{*}{ MATERIAL } & \multicolumn{3}{|c|}{$\boldsymbol{P} / \boldsymbol{f}[\mathbf{\%}]$} \\
\cline { 2 - 4 } & $100 / 1$ & $100 / 2$ & $100 / 3$ \\
\cline { 2 - 4 } & \multicolumn{3}{|c|}{$\boldsymbol{P} / \boldsymbol{f}\left[\mathbf{W} / \mathbf{m . s}^{-1}\right]$} \\
\cline { 2 - 4 } & $100 / 15,24$ & $100 / 30,48$ & $100 / 45,72$ \\
\hline PP & GROOVE 1 & GROOVE 2 & GROOVE 3 \\
\hline
\end{tabular}

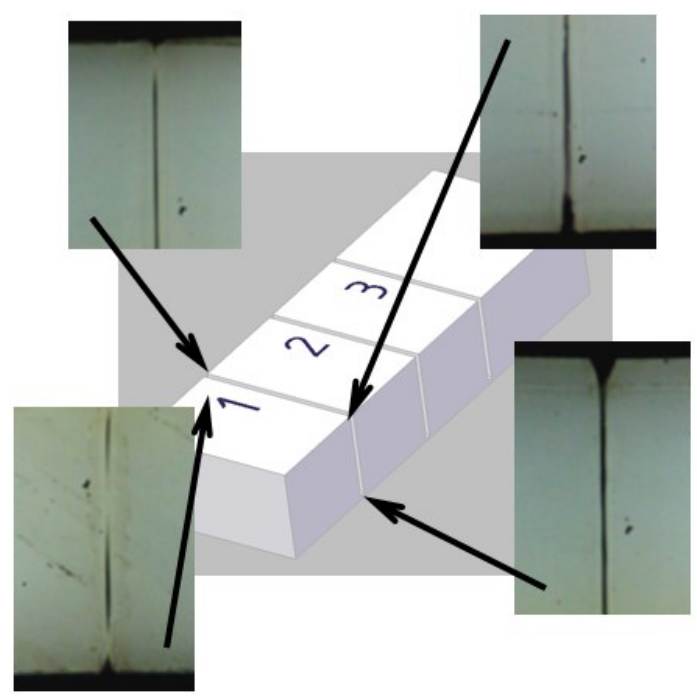

Fig. 2. Samples for experiment

To measure material samples, only grooves 1 and 3 were selected for comparison when sample 1 formed at a cutting speed of $f=15.24 \mathrm{~mm} \cdot \mathrm{s}^{-1}$ was cut across the entire thickness and sample 3 formed at the cut speed of $f=45.72 \mathrm{~mm} . \mathrm{s}^{-1}$, in which the laser beam has not passed the full thickness of material, as well as the sample 2.

\section{Exploration of surface using FTIR infrared spectroscopy}

The non-destructive FTIR analytical method enables based on various IR interactions, to identify and structurally characterize typical bonds in a given organic substance. The principle of this method lies in an examining of the absorption of IR radiation passing through a material. It changes the rotationally vibrational energy states of the molecules, depending on the change in the dipole moments of the molecules of this substance. Each atom in the molecule exhibits vibration around its equilibrium position, the frequency of 
this vibration being determined by the mass of the parts involved and the bond strength. The frequency of radiation can resonate at certain frequencies with molecular vibrations, and the energy of this radiation can thus be absorbed at the same time. [4]

Measurements were making $25^{\circ} \mathrm{C}$ and atmospheric pressure.

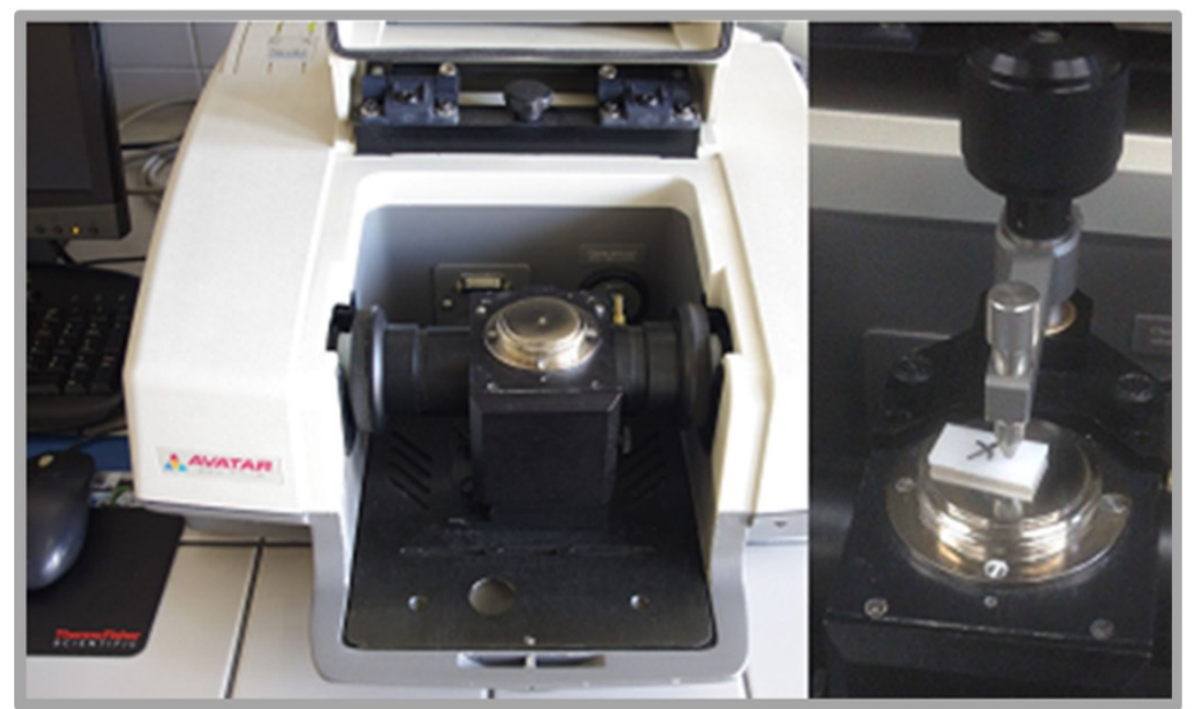

Fig. 3. Nicolet Avatar 320 ATR

\section{Exploration of surface using X-ray diffraction analysis}

The influence on the structure caused by the laser beam from the point of view of the change of crystalline structure was also assessed using the PAN alytical X'Pert PRO diffractometer (refer to: Fig. 4). It is a device capable of rendering scattering of high quality, by means of X-rays, of crystalline matter, of high monochromatic ray, of very precisely defined wavelength. The geometry of the arrangement is so-called BraggBrentanova, where the sample is located in the middle of the circle around which the X-ray radiation source and its detector move fluently. [5- 6]

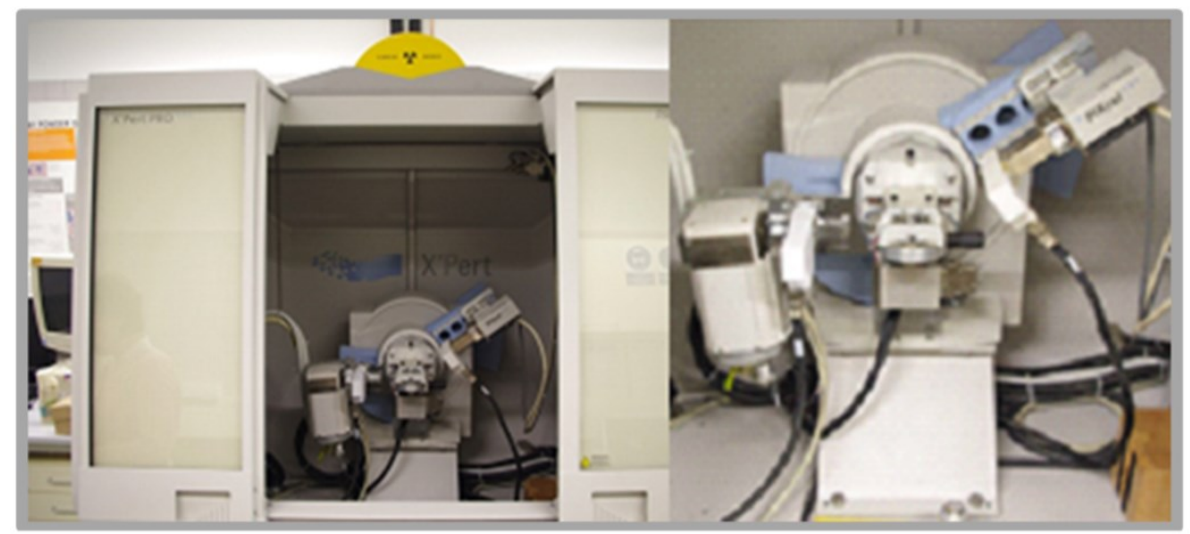

Fig. 4. Diffractometer PANalytical X'Pert Pro 


\section{Measurement and evaluation results FTIR}

Also here the experiment was performed in the cut $1(\mathrm{P}=100 \mathrm{~W} ; \mathrm{f}=15.24 \mathrm{~mm} . \mathrm{s}-1)$, i.e., at the point of maximum irradiated material. The cutting area was then compared with the base material (non-irradiated area) of the initial composition.

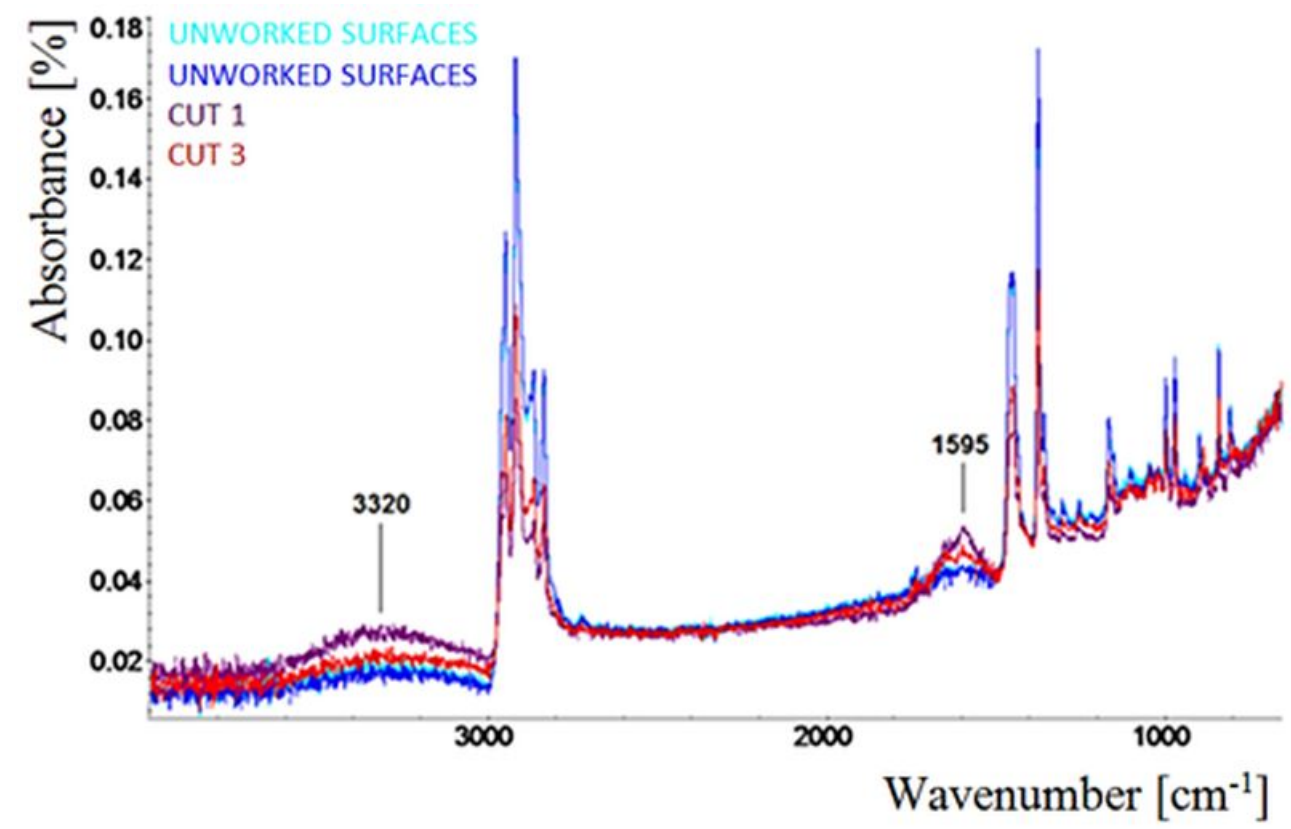

Fig. 5. IR spectra of individual lasr-irradiated surface

In the case of drawn-out curves of the PP material (refer to: Fig. 5), it possible to notice that some constitutional changes took place here. Peaks in the wavelength range $1595 \mathrm{~cm}-1$ represent an increase in ketone bonds. At a location below the wavelength of $3000 \mathrm{~cm}^{-1}$, a strong occurrence of four narrow peaks can be read. According to literature, pair of peaks closer to this wavelength is related to $-\mathrm{CH}_{3}$ bonds. The second pair of peaks, toward a lower wavelength, represents the presence of $-\mathrm{CH}_{2}$ bonds. An increase in the IR-absorption was recorded in a broader area around $3320 \mathrm{~cm}^{-1}$, which is associated with an increase in $-\mathrm{O}-\mathrm{H}$ bonds. [7-10]

The presence of $-\mathrm{O}-\mathrm{H}$ and the ketone bonds in the PP sample are caused by the degradation of the polymeric chain. The loss of the $-\mathrm{CH}_{2}$ bonds signifies the breakdown of the major polymer chain and, in the case of the loss of $\mathrm{CH}_{3}$ bonds, is the splitting of the side chain of the chain.

\section{Measurement and evaluation results X-ray diffraction}

By diffraction analysis it was found that PP is a semi-crystalline material with the crystallinity of $69.32 \%$. The irradiated area at the cutting point represents a smaller decrease of the crystalline part to $68.44 \%$, resulting in a decrease in crystallinity of approximately $0.9 \%$.

An X-ray diffractometer analysis confirmed the polymorphic ability of PP. [11] 
In terms of polymorphism of PP, crystallization in monoclinic phase $\alpha$, hexagonal $\beta$ and triclinic $\gamma$, can be expected. [12]

After laser machining, the monoclinic phase $\alpha$ increased by $8 \%$ at the expense of the hexagonal phase $\beta$, while in the unmolded base (non-irradiated) material the phase $\beta$ was originally represented in larger quantities.

Changing the $\alpha$ and $\beta$ phases is possible when the thermodynamic conditions of the recrystallization are met.

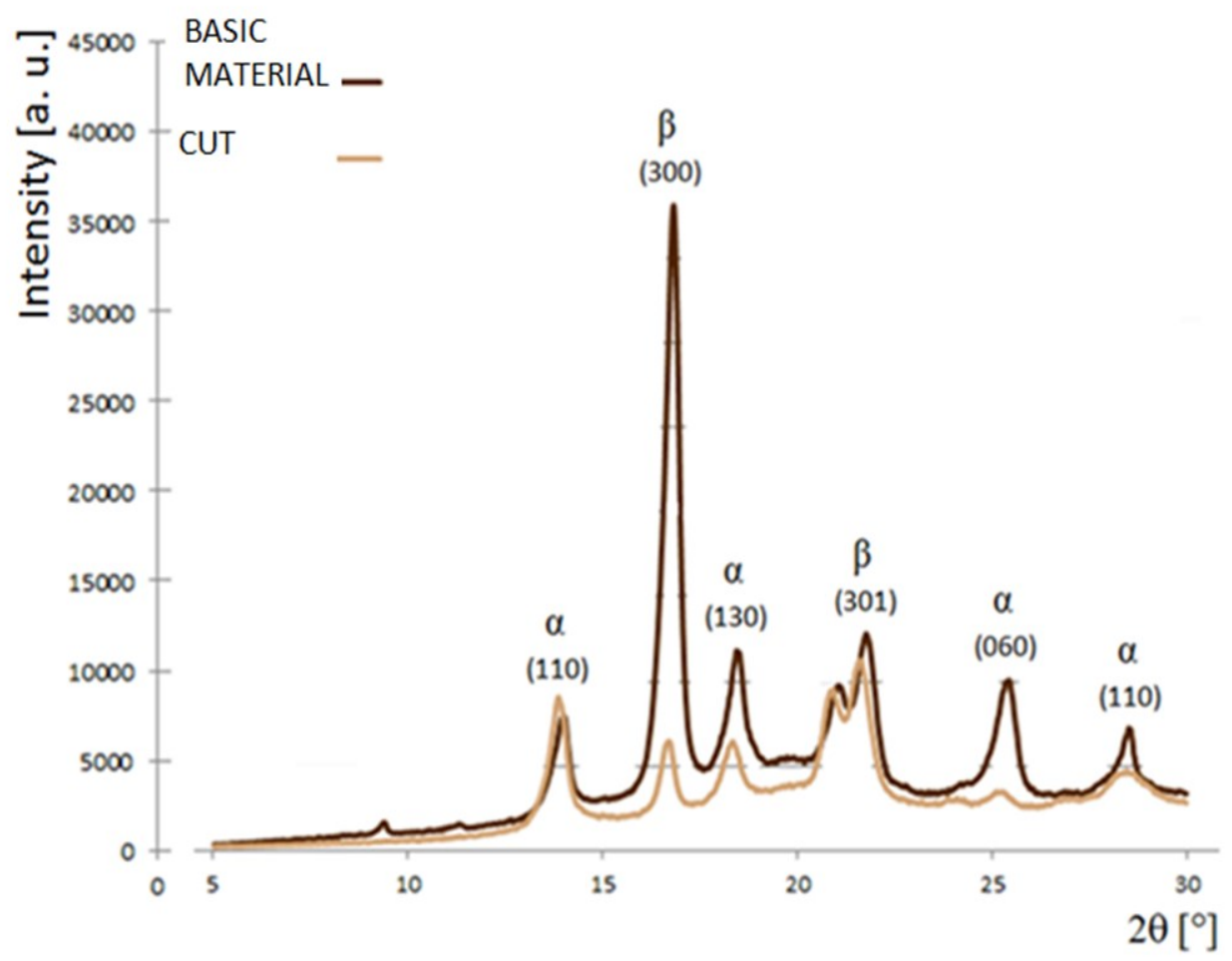

Fig. 6. RTG diffraction image

In the case of laser irradiation, it is possible to assume the effect of increased temperature and subsequent slow cooling suitable for growth of the $\alpha$ modification. The presence of the $\alpha$ or $\beta$ phase was calculated as the area under the curve of an adequate proportion after subtraction the amorphous background.

Table 2 gives data on the representation of phases of non-irradiated base material in which phase $\beta$ is about $65 \%$. For polypropylene, this is a common phenomenon unless a nucleating agent has been added to the material that could change the modification. 
Table 2. Analysis of the semi crystalline fraction of the base material

\begin{tabular}{|c|c|c|c|c|c|c|c|}
\hline PP & $\alpha$ & $\boldsymbol{\beta}$ & $\alpha$ & $\boldsymbol{\beta}$ & $\boldsymbol{\beta}$ & $\alpha$ & $\alpha$ \\
\hline $\begin{array}{l}\text { Settings } \\
2 \theta\left[^{\circ}\right]\end{array}$ & 13,8 & 16,8 & 18,4 & 21,2 & 21,7 & 25,4 & 28,5 \\
\hline $\begin{array}{l}\text { Maximum } \\
\text { Intensity [a. u.] }\end{array}$ & 4739 & 33472 & 6975 & 4822 & 9743 & 6453 & 3069 \\
\hline Area & 4692 & 19761 & 8319 & 8360 & 7234 & 4816 & 1471 \\
\hline \multicolumn{8}{|c|}{ PP basic material } \\
\hline Phase & \multicolumn{2}{|c|}{$\alpha$} & \multicolumn{2}{|c|}{$\boldsymbol{\beta}$} & \multicolumn{3}{|c|}{ Summary } \\
\hline Area & \multicolumn{2}{|c|}{19298} & \multicolumn{2}{|c|}{35355} & \multicolumn{3}{|c|}{54653} \\
\hline Area $[\%]$ & \multicolumn{2}{|c|}{35,31} & \multicolumn{2}{|c|}{64,69} & \multicolumn{3}{|c|}{100} \\
\hline
\end{tabular}

Table 3 shows data on the representation of the phases of the irradiated material at cutoff point 1 . In the irradiated state, polypropylene has a $\beta$ phase of $55 \%$. Using X-ray diffraction, it was found that the irradiated PP contained lower $\beta$ (hexagonal) values of approximately $10 \%$, resulting in an increase in the $\alpha$ (monoclinic) phase modification.

Table 3. Analysis of phase of semi crystalline of irradiated material

\begin{tabular}{|c|c|c|c|c|c|c|c|c|}
\hline PP & $\alpha$ & $\beta$ & $\alpha$ & $\beta$ & $\beta$ & $\alpha$ & $\alpha$ & $\alpha$ \\
\hline $\begin{array}{l}\text { Settings } \\
2 \theta\left[^{\circ}\right]\end{array}$ & 13,9 & 16,7 & 18,3 & 22 & 21,6 & 24 & 25,2 & 28,5 \\
\hline $\begin{array}{l}\text { Maximum } \\
\text { Intensity [a. u.] }\end{array}$ & 6966 & 3866 & 3675 & 7467 & 4658 & 359 & 813 & 1687 \\
\hline Area & 5475 & 3206 & 5139 & 10817 & 2215 & 540 & 517 & 1752 \\
\hline \multicolumn{9}{|l|}{ PP cut 1} \\
\hline Phase & \multicolumn{2}{|c|}{$\alpha$} & \multicolumn{2}{|c|}{$\boldsymbol{\beta}$} & \multicolumn{4}{|c|}{ Summary } \\
\hline Area & \multicolumn{2}{|c|}{13423} & \multicolumn{2}{|c|}{35355} & \multicolumn{4}{|c|}{29661} \\
\hline Area $[\%]$ & \multicolumn{2}{|c|}{45,25} & \multicolumn{2}{|c|}{54,75} & \multicolumn{4}{|c|}{100} \\
\hline
\end{tabular}

In sample from PP material, after the laser machining, the content of the monoclinic phase $\alpha$ was increased to the detriment of the hexagonal phase $\beta$, whereas in the origin material (non-irradiated), originally in the larger amount was represented by phase $\beta$ in the presence of $-\mathrm{OH}$ and the ketone bonds in the sample PP represents degradation of the polymer chain (refer to: Figure 6).

Using XRD, it was found that irradiated PPs contained lower $\beta$ (hexagonal) phases of about $10 \%$ as shown (see Table 4 ), which led to an increase in the $\alpha$ (monoclinic) phase modification allowed by thermodynamic laser machining. 
Table 4. Comparison of the semi crystalline fraction phase for PP

\begin{tabular}{|l|c|c|c|}
\hline \multicolumn{4}{|c|}{ PP basic material } \\
\hline Phase & $\boldsymbol{\alpha}$ & $\boldsymbol{\beta}$ & Summary \\
\hline Area & 19298 & 35355 & 54653 \\
\hline $\begin{array}{l}\text { Content } \\
\%]\end{array}$ & 35,31 & 64,69 & 100 \\
\hline \multicolumn{3}{|c|}{ PP cut 1 } & Summary \\
\hline Phase & $\boldsymbol{\alpha}$ & $\boldsymbol{\beta}$ & 29661 \\
\hline Area & 13423 & 35355 & 100 \\
\hline $\begin{array}{l}\text { Content } \\
{[\%]}\end{array}$ & 45,25 & 54,75 & \\
\hline
\end{tabular}

Infrared Vibrational Spectroscopy confirmed the constitutional changes of the chains, in this case the assumed degradation character.

\section{Conclusion}

At present, laser technology is an indispensable link in a wide range of industries, including engineering, medicine, research and more. In spite of all its advantages, however, it is a high-energy source of radiation, so the heat-affected zone at the cutting area occurs during machining. The size of this area varies, depending on many factors, such as laser wavelength, technological parameters, and the thermal conductivity of the workpiece plays a big role here. Although plastics are among materials with low thermal conductivity, there is a very high temperature at the cutting point for a short time, and the heat is propagated into the internal material volumes. As mentioned above, due to the increased temperature, the material may have different undesirable changes but will only occur in close proximity to the cutting point.

For experimental machining and subsequent study using Fourier Transform Infra-Red vibration spectroscopy, PP was selected. A qualitative comparison of IR spectra of surfaces treated by a laser beam with a non-irradiated surface was performed. Using infrared vibrational spectroscopy, it has been found that after laser beam processing of samples from PP material, certain structural changes have occurred. The diffractometer found changes in the content of crystalline phases in the base material and in the material after irradiation. XRD diffraction analysis showed a reduction in the crystalline fraction by irradiation of samples, which can be explained by chain degradation, in accordance with FTIR analysis.

\section{References}

1. I. Maňková, Progresívné technologie (ISBN Vienala, Košice, 2000)

2. V. Ducháček, Polymery : výroba, vlastnosti, zpracování, použití (ISBN VŠCHT, Praha, 2011)

3. J. Mleziva, J. Šňupárek, Polymery (ISBN Sobotáles Praha, 2000)

4. Information on https:// ttp.zcu/files/projects/frvs-3892007/skripta kap3 irspektrome.pdf

5. Information on http://www.iic.cas.cz/www.iic.cas.cz/ grygar/map1L-4.

6. Information on http :

//www.kmt.tul.cz/edu/podklady_kmt_magistri/MSS/vyukove_texty_XRD.pdf

7. Information on http://webspectra.chem.ucla.edu 
8. Information on http://www1.udel.edu/chem/fox/chem333

9. Information on http://old.vscht.cz/lms/Zverze/Infrared.htm

10. Information on http://www2.ups.edu/faculty/hanson/Spectroscopy/IR/IRfreqencies.html

11. L. Lapčík, M. Raab, Nauka o materiálech II (UTB-Academia centrum, Zlín, 2004)

12. J. Aurrekoetxea, M. Sarrionandia, I. Urrutibeascona, Ml. Maspoch, Polymer, 44 (2003) 